\title{
Implementasi Bisnis Spaghetti Medan sebagai Inovasi Produk dalam Bidang Kuliner di SMAN 1 Cikarang Pusat
}

\author{
Abdul Ghofir ${ }^{1)}$, Genta Sahuri ${ }^{2}$, Dedi Rianto Rahadi ${ }^{3)}$ \\ 1) Fakultas Komputer, Universitas Presiden, geoff@president.ac.id \\ 2) Fakultas Komputer, Universitas Presiden, genta.sahuri@president.ac.id \\ 3) Fakultas Bisnis, Universitas Presiden, dediriantorahadi@president.ac.id
}

\begin{abstract}
ABSTRAK
Spaghetti Medan adalah salah satu jenis makanan kuliner khas Medan yang terkenal dengan kelezatannya. Ini adalah jenis makanan olahan berupa mie khas Medan yang dikombinasikan dengan mie olahan khas Italia. Bahan makanan ini relatif murah sehingga banyak diminati oleh masyarakat menengah ke bawah, khususnya kawula muda. Dari situlah kemudian muncul ide untuk membuat sebuah terobosan bisnis berupa kuliner makanan yaitu Spaghetti Medan yang target pasarnya adalah anak-anak remaja yang masih duduk di bangku sekolah menengah. Kuliner khas Spaghetti Medan ini akan dikemas secara sederhana dalam sebuah kemasan yang menarik, tidak terlalu membutuhkan tempat yang luas, dan mudah dalam proses pembuatan serta penjualannya. Pembeli hanya membeli, kemudian dapat membawanya ke tempat lain untuk mengkonsumsinya. Bisnis ini mudah, sederhana dan tidak terlalu membutuhkan modal yang besar, sehingga dapat dilakukan oleh siapa saja. Dalam hal ini, bisnis ini diimplementasikan kepada para siswa SMA Negeri 1 Cikarang Pusat sehingga mereka yang masih duduk di bangku SMA dapat sambil menjalankan bisnis di masadepannya.
\end{abstract}

Kata-kata Kunci: Mie, Spaghetti, Spaghetti Medan, Bisnis Sederhana

\begin{abstract}
ABSTRACK
Spaghetti Medan is one of a special culinary food of Medan that is known as a delicious food. It is one of processed food in the form of typical Medan noodles combined with typical Italian processed noodles. This food is relatively inexpensive so it is in great demand by the lower middle class, especially the young people. This has led to an idea to create a business in the form of food culinary, namely Spaghetti Medan whose the target market are teenagers who are still in high school. The typical Spaghetti Medan culinary will be packaged simply in an attractive packaging, not really need a large place, easy in manufacturing and selling process. Buyers are able to buy and then take it to another place to consume. This business is easy, simple, and does not really need a large capital so it can be done by anyone. In this case, this business is implemented to the students of SMA 1 Cikarang Pusat.
\end{abstract}

Keywords: Noodles, Spaghetti, Spaghetti Medan, Simple Business

\section{PENDAHULUAN}

Spaghetti Medan adalah salah satu makanan khas asal Medan, yang lezat dan bergengsi ala makanan Italia. Makanan ini banyak digemari oleh anak-anak muda sebagai makanan alternatif khas Italia yaitu spaghetti. Dengan harga yang sangat terjangkau sesuai dengan kantong anak sekolah, rasa yang khas dan tak kalah lezat membuat makanan ini laris manis (Gozal \& Praptiningsih, 2013).

Tidak banyak yang tahu, bahwa sebetulnya proses pembuatan Spaghetti Medan ini sangat mudah dan sederhana. Anak-anak usia remaja dapat dengan mudah mempelajarinya, sebagaimana membuat mie goreng (PT. Mulia Boga Raya Tbk., 2017). 
Di sisi lain, tidak semua siswa SMA adalah anak-anak orang berada. Tidak jarang mereka harus membantu orang tua dalam memenuhi kebutuhan sekolahnya, atau hanya sekedar untuk mencari tambahan sebagai uang jajan.

Berbekal dari persoalan-persoalan yang ada itulah, kemudian timbul gagasan untuk membukakan jalan bagi mereka yang memang membutuhkan maupun mereka yang memang senang untuk berbisnis. Spaghetti Medan adalah solusi bisnis ala siswa sekolah yang mudah, sederhana, dan tidak perlu banyak modal. Selain untuk menambah keahlian dalam hal memasak, bisnis Spaghetti Medan juga sebagai alternatif untuk mencari pemasukan guna mencukupi kebutuhan-kebutuhan sekolah siswa.

\section{METODE PELAKSANAAN}

\subsection{Objek Kegiatan}

Objek dari kegiatan implementasi bisnis ini adalah siswa-siswi SMA Negeri 1 Cikarang Pusat. Mereka pada umumnya adalah siswa-siswi kelas 10 dan 11, atau siswa tingkat 1 dan tingkat 2 di SMA tersebut. Sementara untuk siswa-siswi tingkat akhir tidak bisa bergabung karena mereka tengah sibuk mempersiapkan ujian akhir.

Mereka yang masih duduk di tingkat pertama dan kedua SMA adalah siswa-siswi yang masih mempunyai semangat tinggi dalam belajar, sehingga mereka sangat antusias dalam mengikuti dan menyimak kegiatan ini, seperti yang terlihat pada Gambar 1. Antusiasme mereka begitu nampak pada keceriaan mereka yang sangat menikmati proses demi proses, hingga tak segan maupun canggung untuk membantu dalam persiapan maupun pengolahan bahan.

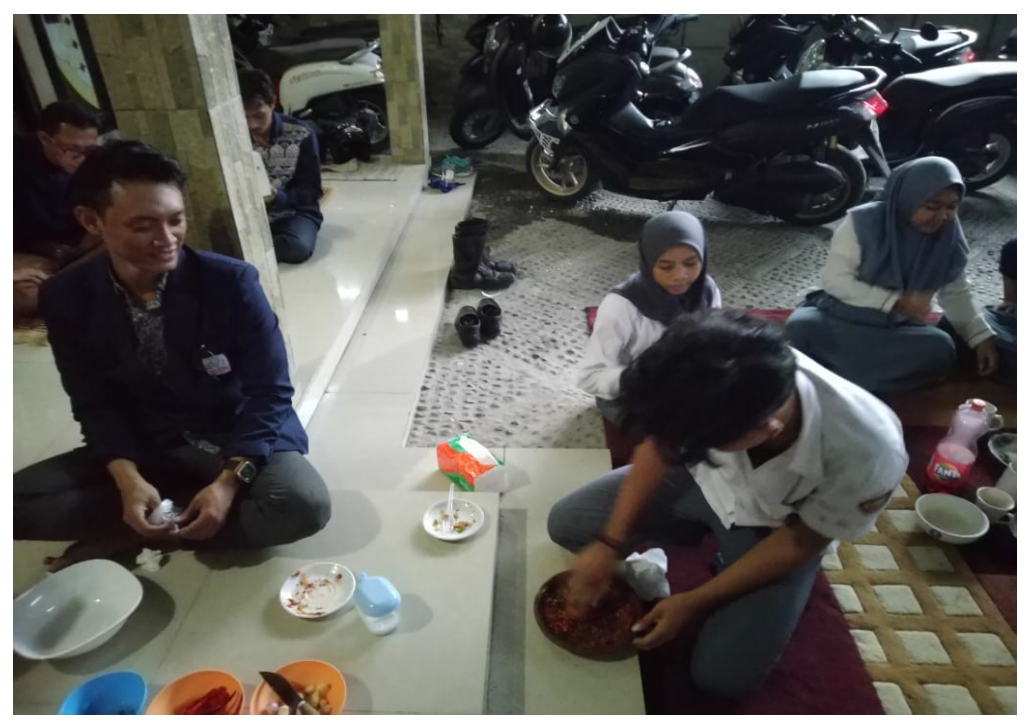

Gambar 1.

Persiapan Pembuatan Spaghetti Medan 


\subsection{Rencana Kegiatan dan Partisipan}

Untuk melaksanaan kegiatan ini, pertama adalah melakukan koordinasi dengan mahasiswa fakultas bisnis. Kemudian bersama mereka, menentukan sekolah mana yang akan dijadikan sasaran implementasi bisnis ini. Ada beberapa sekolah terdekat yang dihubungi, dengan cara mendatangi sekolah-sekolah tersebut melalui organisasi kemahasiswaan sekolah. Dari hasil pendataan dan observasi yang dilakukan, kemudian diputuskan bahwa implementasi ini dilakukan di SMA Negeri 1 Cikarang Pusat.

Selanjutnya adalah melakukan komunikasi yang lebih intensif dengan pihak OSIS SMA Negeri 1 Cikarang Pusat, guna melakukan persiapan kegiatan mulai dari apa-apa saja yang diperlukan, siswa kelas berapa, tempat, hingga waktu pelaksaan. Dari situlah kemudian diputuskan bahwa kegiatan ini akan dilaksanakan di salah satu ruang SMA tersebut, yang beralamat di Jl. Beruang Raya No. 9 Jaya Mukti, Kecamatan Cikarang Pusat, Bekasi, dengan melibatkan siswa dan siswi kelas 10 dan 11, yang rencana pelaksaannya adalah Hari Sabtu, 7 Desember 2019 jam 13.00 WIB. Mereka adalah siswa-siswi tingkat pertama dan kedua yang memiliki waktu lebih luang dan semangat yang tinggi untuk belajar.

\subsection{Pelaksanaan Kegiatan}

Rencana kegiatan yang semula diadakan di salah satu ruang kelas SMA Negeri 1 Cikarang Pusat terpaksa harus berubah. Hal ini terjadi karena adanya acara kegiatan lain di sekolah tersebut yang tertunda, dari yang semula seharusnya selesai jam 12.00 ternyata harus selesai jam 17.00. Beruntung, mahasiswa President University sangat sigap. Melihat adanya perubahan yang terjadi di lokasi acara semula, kemudian mahasiswa memutuskan untuk memindahkan acara di salah satu rumah mahasiswa demi tetap terselenggaranya acara yang telah direncanakan. Rumah mahasiswa sebagai pengganti tempat kegiatan tersebut tidak terlalu jauh, sehingga siswa-siswi SMA pun tetap bersedia hadir tanpa mengurangi antusiasme mereka untuk belajar memasak dan berbisnis. Hal ini terlihat dari bagaimana mereka mengikuti kegiatan ini. Nampak seperti pada gambar 1 diatas, mereka membantu kakak mahasiswa dalam mempraktekkan memasak dari mulai persiapan, mengulek bumbu-bumbu, hingga menyimak bagaimana proses menggoreng seperti terlihat pada Gambar 2 dan Gambar 3 berikut. 


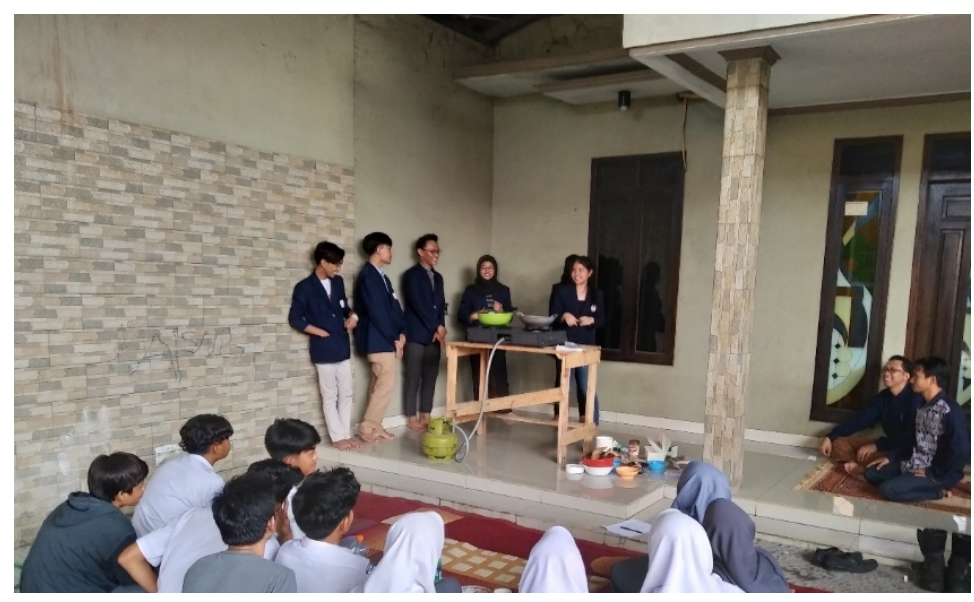

Gambar 2.

Persiapan Memasak Spaghetti Medan

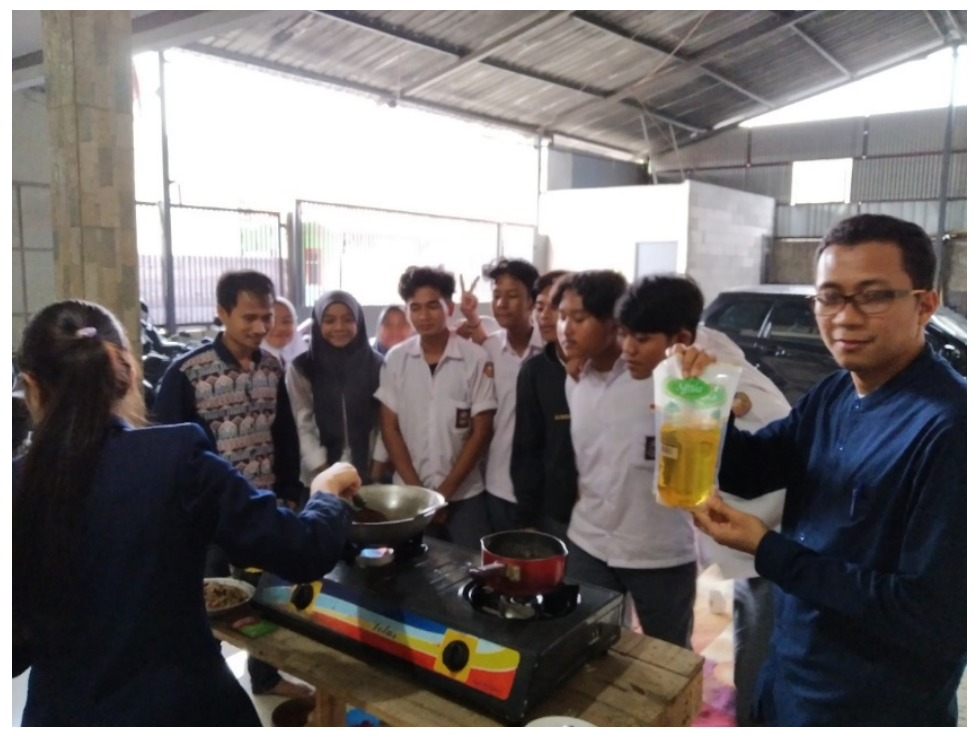

Gambar 3.

Proses Pembuatan Spaghetti Medan

Dalam proses pembuatan Spaghetti Medan ini, mahasiswa President University menjelaskan terlebih dahulu bahan-bahan apa saja yang perlukan, peralatan, bahan utama termasuk merek dagang berupa mie olahan yang menjadi bahan pokok dalam makanan ini, bumbu-bumbu hingga bagaimana cara memasaknya (Awlia, 2020). Ada dua jenis masakan yang diperagakan di sini. Pertama adalah spaghetti goreng, dan yang kedua adalah spaghetti berkuah. Dengan 2 jenis menu masakan tersebut, maka penikmat dapat memilih sesuai dengan selera (fimela.com, 2016).

Setelah proses memasak selesai, langkah berikutnya adalah bagaimana mengemas makanan ini agar lebih menarik. Mahasiswa menjelaskan bagaimana membuat kemasan box atau wadah Spaghetti Medan yang terlihat sederhana tapi menarik dan bagaimana cara mengemasnya. Setelah selesai semuanya, tibalah saatnya untuk mencicipi bagaimana 
rasanya Spaghetti Medan. Rasanya sangat nikmat dan lezat, tidak kalah dengan spaghetti yang ada di luar sana, seperti terlihat pada Gambar 4 dan Gambar 5.

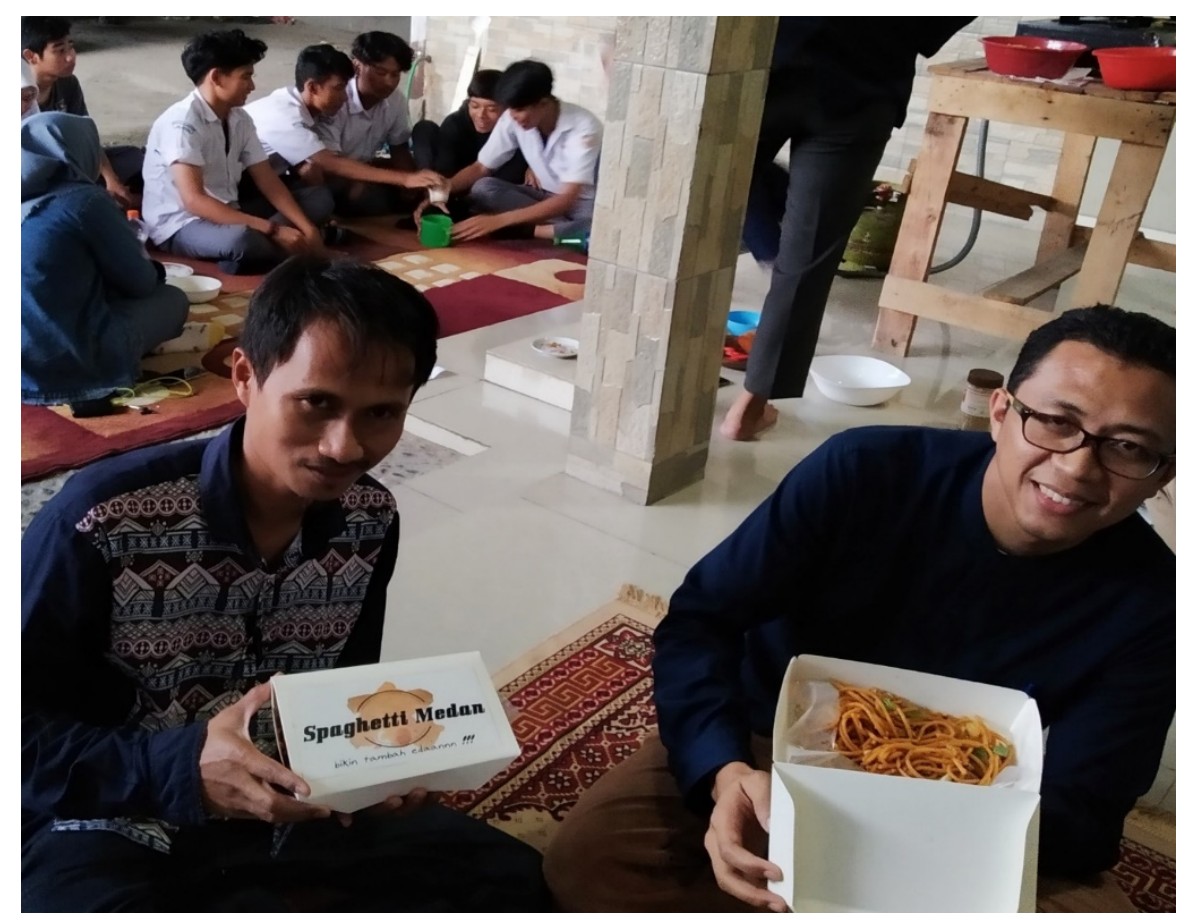

Gambar 4

Spaghetti Medan dalam Kemasan Utama

Siswa-siswi SMA sangat menikmati makanan ini. Selain rasanya yang khas, hal ini juga menambah wawasan dan pengetahuan mereka tentang adanya makanan khas negeri sendiri yang tidak kalah enaknya dibanding dengan makanan khas dari negeri lain. Hal ini terbukti dari bagaimana mereka menikmati makanan ini, dari yang semula hanya dijatah 1 porsi per siswa, mereka minta lebih dan tambah. 


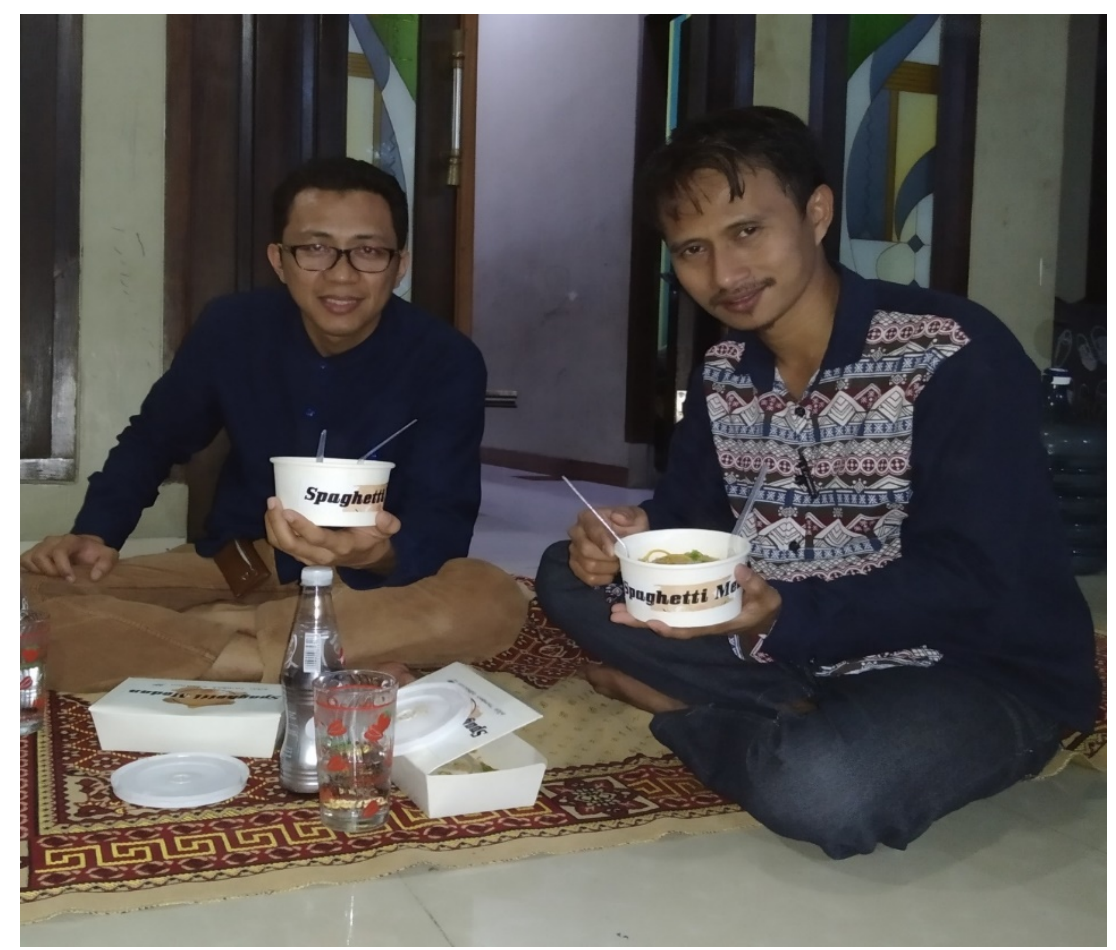

Gambar 5

Spaghetti Medan dalam Kemasan Kedua (Berkuah)

Bersamaan dengan menikmati hidangan hasil karya mahasiswa yang dibuat secara langsung dihadapan mereka, mahasiswa President University selanjutnya menjelaskan kembali bagaimana Spaghetti Medan ini menjadi sebuah bisnis yang bisa mereka garap di sekolah mereka maupun di lingkungan mereka tinggal. Dijelaskan pula mengenai rincian modal, cara mendapatkan bahan, strategi pemasaran dan bagaimana mengolah keuangan agar bisnis semakin berkembang.

\section{HASIL DAN PEMBAHASAN}

Spaghetti Medan adalah makanan yang terbilang masih langka. Padahal di beberapa tempat lain terutama di daerah asalnya, makanan ini merupakan makanan yang difavoritkan oleh remaja. Terbukti dengan hanya baru satu kali implementasi saja, ini sudah membuat sebuah kejutan bagi siswa-siswi SMA 1 Cikarang Pusat. Dengah demikian, makanan ini dapat dijadikan sebagai sebuah terobosan yang merupakan alternatif bagi pencinta spaghetti. Dari sisi bisnis, ini juga sangat menjanjikan. Jika dikembangkan secara terus menerus, makanan ini dapat menjadi makanan khas daerah yang berpotensi untuk bersaing di kancah internasional.

Ada beberapa hal yang harus ditentukan agar bisnis ini berkembang dengan baik dan semakin dikenal oleh publik. Hal tersebut adalah strategi pasar, segmentasi, target pasar, dan positioning. Berikut ini penjelasannya. 


\subsection{Strategi Pasar}

Dalam usaha mengembangkan bisnis ini, perlu di atur strategi bagaimana agar Spaghetti Medan ini semakin di kenal dan disukai oleh remaja khususnya anak-anak sekolah. Perlu kejelian untuk bisa mengatur langkah-langkah mempublikasi Spaghetti Medan agar lebih di kenal di masyarakat. Untuk mendukung keputusan bagaimana strategi yang harus ditempuh, perlu beberapa hal seperti disebut pada poin-poin berikutnya (Herdiyansyah, Ikhwana, \& Kurniawati, 2015).

\subsection{Segmentasi}

Segmentasi adalah klasifikasi pembeli yang akan menentukan target pasar. Klasifikasi bisa berdasarkan usia, dari mulai anak-anak hingga orang dewasa, maupun berdasarkan komunitasnya. Misal, siswa-siswi sekolah menengah, perguruan tinggi, maupun khalayak umum (Sancoko, 2015).

\subsection{Target Pasar}

Dengan melihat segmentasi pada poin sebelumnya, kemudian selanjutnya adalah penentuan target pasar. Dalam hal ini, target pasar Spaghetti Medan utamanya adalah kalangan siswa sekolah baik menengah maupun atas, hingga perguruan tinggi (Winarta, 2015).

\subsection{Positioning}

Agar cita rasa yang khas dari Spaghetti Medan ini dapat dikenali oleh masyarakat, maka dalam produk ini ditambah bahan baru yang akan membedakan antara Spaghetti Medan dengan spaghetti lainnya, yaitu dengan menambahkan bahan seperti andaliman dan kacang bubuk sehingga tampilan lebih menarik, rasa lebih unggul, dan kualitas sangat baik. Inilah yang menjadi ciri khusus dan konsumen bisa dengan mudah mengenalinya (Wulandari, 2017).

\section{KESIMPULAN}

Bisnis kuliner saat ini banyak digemari oleh masyarakat. Baik yang sekedar hobi memasak, maupun yang memang pebisnis professional. Bisnis kuliner saat ini adalah bisnis yang menjanjikan. Bisnis ini dapat meraup keuntungan yang sangat besar. Meski demikian, bisnis kuliner ini juga punya risiko, karena makanan mempunyai daya tahan kesegaran yang terbatas. Akan tetapi, jika sudah memiliki pangsa pasar yang bagus, pelanggan yang setia, maka bisnis kuliner akan menghasilkan keuntungan yang berlipat ganda.

Hal yang paling penting dalam mempersiapkan bisnis kuliner apapun (termasuk Spaghetti Medan) ini adalah mental. Mental yang kuat akan mengalahkan segala 
kekhawatiran, ketakutan, maupun keragu-raguan pada kegagalan atas persaingan. Selanjutnya adalah masalah operasional atau teknis pelaksaan bisnis. Perlu disiapkan segala sesuai yang berkaitan dengan proses pembuatan, agar menghasilkan sajian makanan yang memuaskan.

\section{UCAPAN TERIMA KASIH}

Kegiatan ini telah berjalan dengan baik sesuai dengan yang telah direncanakan. Meski sebelumnya ada beberapa kendala mengenai tempat pelaksaan, namun telah dapat diatasi dengan baik sehingga tidak berpengaruh buruk terhadap jalannya acara. Untuk itu, terima kasih dan penghargaan yang setinggi-tingginya kepada para peserta kegiatan yaitu siswa-siswi SMA Negeri 1 Cikarang Pusat, Mahasiswa Jurusan Manajemen Fakultas Bisnis President University yang namanya tercantum dalam Lampiran 1, yang telah bekerja keras dengan peran dan fungsi kerja masing-masing yang sangat luar biasa.

\section{REFERENSI}

Awlia, I. (2020). Spaghetti Medan/Mie Lidi Gorenk Khas Sumut. Diunduh dari https://cookpad.com.

fimela.com. (2016). Resep Mie Gomak Khas Medan. Diunduh dari https://www.fimela.com

Gozal, A., Praptiningsih, M. (2013). Pengelolaan dan Pengembangan Usaha Mie Instan Pada Perusahaan Keluarga PT. X Di Sidoarjo (Pada Aspek Sumber Daya Manusia). AGORA, 1(1), 1-17.

Hardiyansyah, A., Ikhwana, A., Kurniawati, R. (2015). Analisis Strategi Pemasaran Usaha Mie Basah (Studi Kasus di PD. Lugina - Garus). Jurnal Kalibrasi, 13(1), 1-13.

PT. Mulia Boga Raya Tbk. (2017). Tips Memasak Resep Spaghetti Instan. Jakarta: Prochiz Taste Better. Diunduh dari: https://dapurkejuprochiz.com

Sancoko, A.H. (2015). Strategi Pengembangan Bisnis Usaha Kuliner Makanan dan Minuman pada Depot Time To Eat Surabaya. AGORA, 3(1), 185-194.

Winarta, M. (2015). Strategi Pengembangan Bisnis Makanan pada Usaha Depot Dapur Jawa. AGORA, 3(1), 463-469.

Wulandari, R. (2017). Analisis Pengembangan Strategi Bersaing Pada Café Coffee Q Medan. Diunduh dari http://repositori.usu.ac.id 


\section{LAMPIRAN}

Lampiran 1.

Daftar Mahasiswa Pelaksana Kegiatan

\begin{tabular}{|c|l|l|l|}
\hline No. & \multicolumn{1}{|c|}{ NIM } & \multicolumn{1}{c|}{ Nama } & \multicolumn{1}{c|}{ Peran } \\
\hline 1 & 014201905073 & Esra Simanjuntak & Koordinator acara \\
\hline 2 & 014201905067 & Baihaqi Nauwfal & Perencana acara \\
\hline 3 & 014201905060 & Putri Fatma S & Pengatur produksi \\
\hline 4 & 014201905022 & Lutfi Dico Febrianto & Koordinator peserta \\
\hline 5 & 014201905066 & Sefti Yanti Purba & Pengatur keuangan \\
\hline 6 & 014201905039 & Muhamad Afrizal S. & Penyedia bahan produksi \\
\hline 7 & 014201905076 & Husni Mubarok & Logistik \\
\hline
\end{tabular}

\section{Lampiran 2.}

Tim Pelaksana dan Peserta
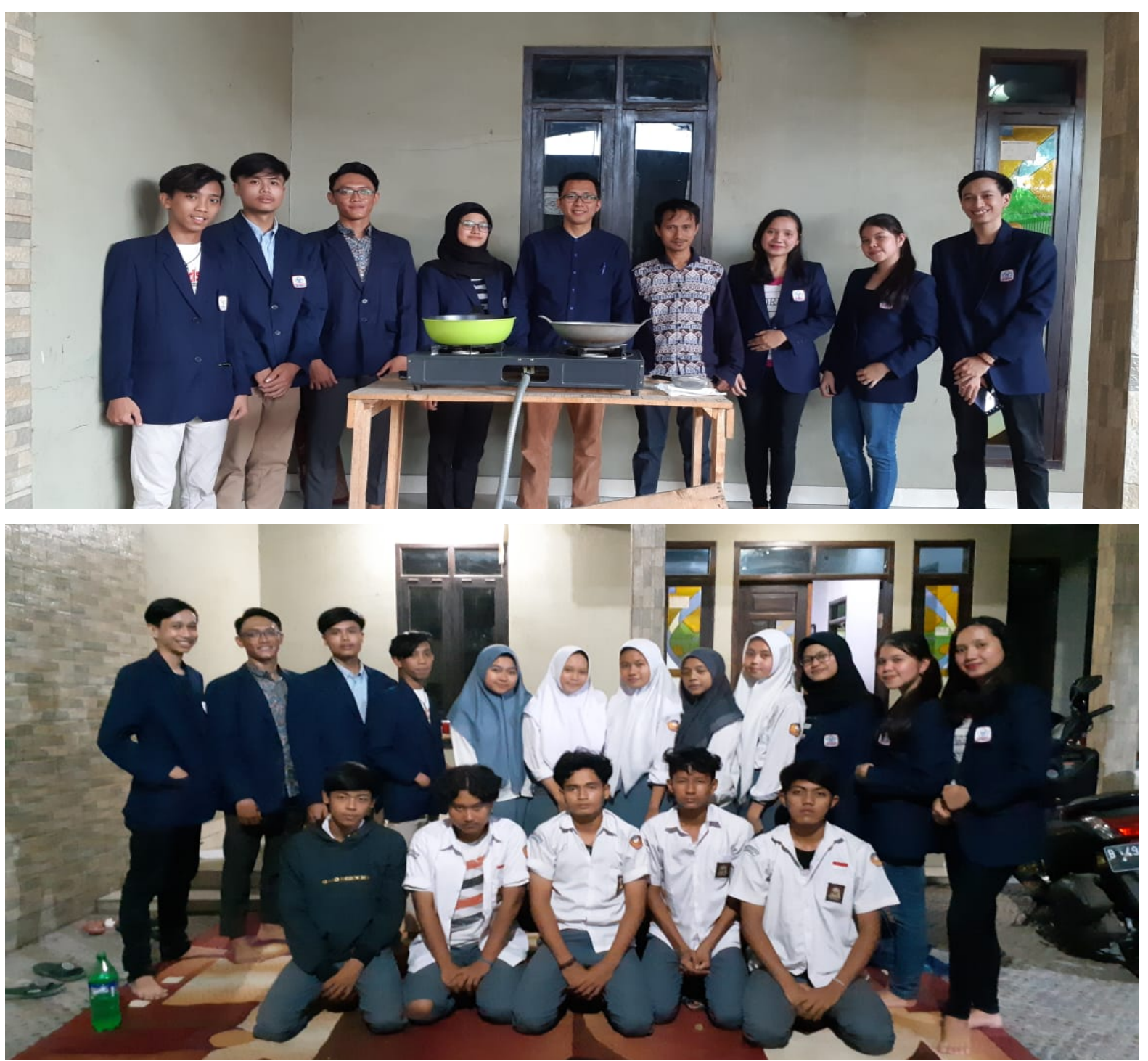
Lampiran 3.

Berita Acara Kegiatan

\section{BERITA ACARA KEGIATAN}

Yang bertandatangan di bawah ini,

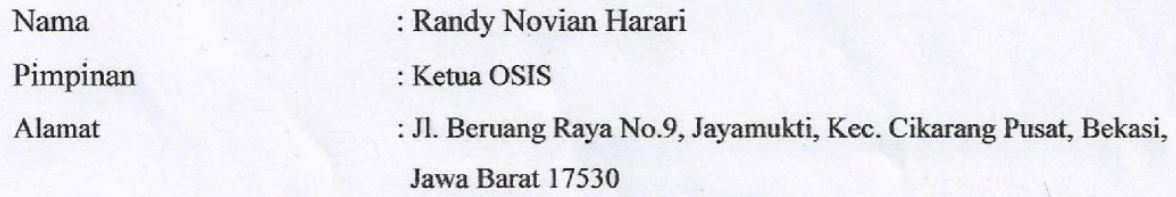

Dengan ini menyatakan bahwa nama-nama dibawah ini memang benar melakukan pengabdian masyarakat atas nama President University dengan judul "IMPLEMENTASI BISNIS SPAGHETTI MEDAN SEBAGAI INOVASI PRODUK DALAM BIDANG KULINER UNTUK MAHASISWA DAN PELAJAR" pada 07 Desember 2019

Nama Koordinator Kegiatan : Baihaqi Nawfal

$\begin{array}{ll}\text { Anggota } & : \text { Esra Simanjuntak } \\ \text { Anggota } & : \text { Putri Fatma S } \\ \text { Anggota } & : \text { Lutfi Dico Febrianto } \\ \text { Anggota } & : \text { Sefti Yanti Purba } \\ \text { Anggota } & : \text { Muhamad Afrizal Sardadianto } \\ \text { Anggota } & : \text { Husni Mubarok } \\ \text { Nama Dosen Pembimbing } & : \text { Abdul Ghofir }\end{array}$

Genta Sahuri

Demikian Surat keterangan ini dibuat dengan penuh kesadaran dan tanggung jawab tanpa ada

unsur pemaksaan di dalam pembuatannya untuk dapat digunakan sebagaimana mestinya.

Cikarang, 02 Desember 2019 Yang menyatakan,

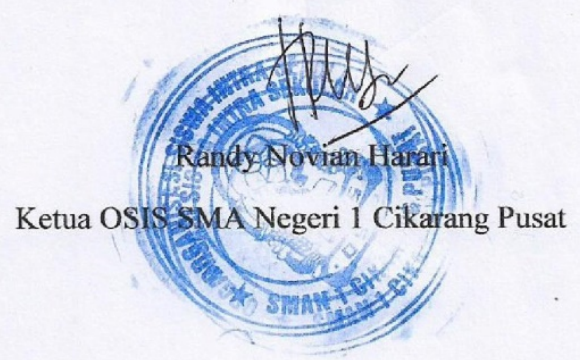

